\title{
7. The climate is changing Russia: from a hydrocarbon to an ecological culture
}

In this concluding chapter I will bring together the features of the Russian hydrocarbon culture and the practices of Putin's fossil-inspired geo-governmentality in the context of a changing global climate. Putin's Russia continues the centuries-old practices of an empire that is violent towards its own people and the outside world and is simultaneously unable to utilize the bountiful resources that Russia possesses, which can be part of the solution of a healthy planet. Therefore, I want to discuss not only the gloomy past and the first, but far too inadequate steps that this regime has taken towards this global goal, but also provide a blueprint and a vision for a resilient and sustainable Russia. This vision stems not only from the same geographical realities as the criticized geo-governmentality of the Putinite hydrocarbon culture, but also from a knowledge of the Russian national identity and culture. The task of unleashing the spatial and societal processes that will turn Russia into an internally strong and internationally respected player is difficult, but certainly not impossible. This requires a rethinking of the objectives and rules of the game in both domestic and cross-border contexts: how will Russians foster the necessary change from within, and how can Russia's partners enhance this through their efforts in the spheres of business and politics?

\section{THE INEVITABILITY OF CHANGE: WILL RUSSIA SUFFER OR BENEFIT FROM IT?}

The scientific evidence and political consensus built up over the past decades means that climate change is not hitting us out of the blue. It is not a 'black swan' in today's global perspective; the progress and severity of climate change does not or should not come as a surprise to leaders. However, in line with the image constructed by Putin's regime, the negative societal impacts of advancing climate change will probably be 
unexpected for many Russians. As I showed in previous chapters, fossil energy, political power and climate denial are intertwined in Russia to the extent that an ambitious climate policy with the objective of reducing emissions, and thus engaging in climate mitigation and transition from a fossil-based energy system to a carbon neutral one, will be an extremely difficult task. The political leadership of the country may even see the effects of climate change as, all things included, beneficial for Russia. Others, namely the United States, several European countries and China, will suffer more than Russia (cf. Graybill 2019), so it must be a beneficial process for the Eurasian territorial giant. The studies illustrating the potential beneficial economic effects of climate change, such as the one by Burke and colleagues (2015) regarding the regionalized economic impacts of climate change, and another focusing on governmental expenditures in Russia (Leppänen et al. 2017), encourage the Russian leadership to cling to the narrative about the beneficial effects of climate change for Russia. This story has been told to Russians since at least the 1990s (for example, N. Tynkkynen 2010): global warming, if it happens, will for natural reasons benefit Russia. The famous slogan coined by President Putin in the 2000s on the changing climate - "we need less fur hats in the future" - is consistent with the possible zero-sum calculations behind the denialist narrative and political stance. If this thought is truly driving the words and deeds of the Putin regime's geo-governmentality, as I suggest in this book, the idea of Russia as a surrounded fortress that has permeated political thought is profoundly biasing the security and risk perceptions of the Russian leadership.

The Fortress Russia mentality is well-suited to the general nationalistic rhetoric of the conservative-populist movements - which are enchanted by authoritarianism and its promise to bring order into a world that looks chaotic - that we see growing today from Eurasia to Latin and North America. This parochial view of the world is unable or unwilling to see the cumulative negative effects of climate change as a common problem facing all humanity and all nations. Instead, it looks at global climate governance and the effects of climate change as a zero-sum game. The remedy according to this worldview is not climate mitigation, but thought control at home in the form of climate denial, and free-riding internationally in hopes that others who supposedly and in reality suffer more from global warming will also take care of the mitigation efforts. Furthermore, as the actors that are actually implementing the mitigation measures, such as the EU, happen to be the main customers of Russia's fossil energy resources, the mitigation itself turns into a security threat for the fossil-based regime. 
When looking at the effects of climate change for Russia, I want to emphasize that in addition to direct environmental and societal effects there are others linked to global consequences. These effects, which include drawbacks in human security leading to conflicts and refugee crises in Asia, the Middle East and Africa because of climate induced resource, food and water shortages, are an issue that is nearly fully absent in the Russian discussion on climate change. As we discussed in the previous chapter about the Russian mediascape regarding the climate issue, the line of narrative is that bad things might happen because of climate change, but they won't affect Russia. Still, in addition to the probable impacts of climate change within Russia, the global changes will have an indirect impact on Russia.

In the territory of Russia, the warming climate will increase the frequency of extreme and negative weather phenomena (Trenberth and Fasullo 2012) and infrastructural challenges and economic costs including those of the cherished hydrocarbon industries - brought about by thawing permafrost (Hjort et al. 2018; Schaeffer et al. 2012). The phenomenon of permafrost thaw is in fact a decisive issue both for Russia and the whole world. In global terms, a permafrost meltdown may release such huge volumes of methane into the atmosphere that we might face a runaway greenhouse effect with catastrophic impacts. In Russia, permafrost covers approximately 60 per cent of the country's territory in western, central and eastern Siberia. Infrastructure, from industry and transport to housing, is susceptible to the negative effects of permafrost thaw. The upper layer of soil will become waterlogged and erosion will be accelerated, thus increasing the costs of building and maintaining infrastructures. The majority of Russia's unused hydrocarbon deposits are in the permafrost areas, meaning that the environmental change experienced there will negatively affect the economy of future projects, as well as Russia's ability to export hydrocarbons. This is acknowledged in official governmental documents (Ministry of Energy 2016): as the climate changes, the protection of critical infrastructures will become much more important than today.

In the more northern areas, rising temperatures will be a boon for agriculture, but the gains on these less fertile lands will be offset by decreasing grain production in the most fertile southern areas of Russia. Due to changes in precipitation and evaporation, these areas will become more arid (Belyaeva and Bokusheva 2017). A warmer climate and higher $\mathrm{CO}_{2}$ content in the atmosphere will make the forests of the large coniferous zone of Eurasia grow faster, but forests and forestry in the taiga zone are expected to suffer from the spread of pathogens and a higher frequency of forest fires (La Porta et al. 2008). Finally, health 
problems will be exacerbated and life expectancy reduced due to increasing extreme weather phenomena, such as heatwaves, and by the spread of tropical and sub-tropical diseases and infection-bearing insects towards the north (Revich et al. 2012).

The regional and global feedback processes of intensifying climate change will thus affect Russia in a similar way to the impact they will have on other Northern industrialized societies. However, the present hydrocarbon culture mentality is trying to detach Russia from the global processes and, in fact, from the global community. The parochial Fortress Russia and the nationalistic-conservative shift carried out by the Putin regime makes it impossible to picture Russia having any significant role in the battle against climate change, especially in light of the regime's inability to evaluate the trans-boundary security threats of climate change. As we very well know, climate change is also a security threat par excellence impacting on all nations, including Russia. Therefore, unfortunately, the black swan precedes the white: a climate-related natural disaster in Russia will be the likely trigger for a move towards sustainability in the present political culture, as climate change is not a problem for the leadership of a fossil-dependent and monolithically ruled Fortress Russia. In real terms, not viewed via a socially constructed hydrocarbon culture identity and practices of a fossil energy-driven geo-governmentality, climate change is a problem for the Russian people, businesses and the environment regardless of the mind-set within the leadership of the country. The severity of the climate-induced catastrophe, and how soon it hits Russia, will determine whether Russia is among the leaders of a new climate-neutral world or a laggard unable to profit economically or politically from the transition.

In light of Russia's current strategic outlook, dictated by the hydrocarbon culture, the rapid energy transformation is suboptimal. The largescale shift from hydrocarbons to renewable energy sources (RES) provides energy consumers with more choices, meaning that Russia's control of energy flows becomes a less effective instrument of geopolitical power (see Chapter 4). Furthermore, since the Russian state budget is highly dependent on energy export revenues, a major change in this sector will have a negative impact in many other sectors, including the military build-up. Lastly, political and technological factors mean that Russia is unlikely to pioneer the technology development required for the renewable energy transition. Russia's involvement in international climate policy shows that it strives to use diplomacy to influence international energy and climate policy in a way that discourages change. One key reason for this inactivity is the power produced via a hydrocarbon culture. 
The logic of a hydrocarbon culture seems to be at odds with Russia's potential to transform to a new level of technological progress. An innovative economy, which is a prerequisite for transitioning towards a resilient and sustainable economy built on renewable energies, would require omitting the mentality and practices - the geo-governmentality of a hydrocarbon culture. Instead, Putin's Russia is now trying to more effectively utilize different non-military forms of aggression in order to compensate for the technological lead of Western countries and China. This point of departure is in fact guiding the agenda of the National Security Strategy of Putinite Russia. The document states that direct and indirect political, military, economic and information means are used in the global struggle for power, and to produce 'a strategic deterrent' (Strategiya 2015). A rapid transition to a new technological level, with energy technologies based on RES leading the way, thus poses a security threat for Putin's Russia that needs to be confronted using a wide repertoire of asymmetric and violent means that have recently been labelled as 'hybrid warfare' (Cullen and Reichborn-Kjennerud 2017; Galeotti 2017). Furthermore, in the name of Russia's national interests, Putin's hydrocarbon culture is trying to mobilize the entire Russian society - from individual citizens to major enterprises - behind this hybrid offensive (Chernenko 2012). In summary, the transition to a resilient and sustainable Russia that is able to reap the benefits of the ongoing transition to a new technological level and new RES-based energies is extremely unlikely under the contemporary violence-prone hydrocarbon culture. This is the case despite the fact that RES deployment in Putin's Russia does exist, as I describe below.

\section{FIRST STEPS: RENEWABLE ENERGY DEPLOYMENT WITHIN THE HYDROCARBON CULTURE}

Russia is an energy giant also in terms of RES: it has both large resources and the technologically relatively developed society and economy needed to foster an energy transition towards renewables and a low-carbon economy. Russia has a large bioenergy potential via its forest resources, which are the largest in the world, but its vast territory also provides the potential to develop wind, small-scale hydro, solar and geothermal power in an economically viable way (LUT 2015). Despite this promising starting point, the fact that the political elite has grown so dependent on rents and power derived from hydrocarbons means the hydrocarbon culture in the making that we are witnessing is at odds with the energy transition objectives. Historical path dependencies actually 
dictate today's approach to energy, resources and the environment in Russia. An important factor is the centrality of resource extractive industries in the Russian economy throughout its history - from furs, coal and ore to oil and gas - resulting in economic and environmental practices that resemble those of other colonial contexts in Africa, Asia and the Americas. This historical tendency was accelerated during Soviet era industrialization, which relied on unchecked utilization of natural resources. The vast size of the industries in the natural resource sector is the result not only of political history and large resources per se, but also that of specific resource geographies: the globally important deposits of oil, gas, coal and uranium are not evenly distributed in the Russian Eurasian space. Instead, these industries have required significant infrastructural investments in order to develop resources found mainly in the periphery. Thus, the specific population and resource geographies of the country have led to 'stretched' infrastructures. This factor then amplifies the energy-society loop: the more Russia has been compelled to invest in the energy infrastructures (in gas and oil pipelines, ports and so on) to maintain production volumes allowing a certain level of rents, the more its political choices have been narrowed concerning the energy transition to a carbon-free energy system.

Despite this difficult situation, Russia has officially promoted the use of renewables and an increase in its energy efficiency. All the energy strategies that Russia has approved during the 2000s (Ministry of Energy 2003, 2009, 2017) emphasize the necessity to increase energy efficiency in the Russian economy, from households to the public sector and industry. This plea for higher efficiency is in line with the economic rationale to benefit from using less oil and gas in the Russian economy, and allowing these volumes to be sold on the international markets at a better premium. Moreover, energy efficiency objectives promote the deployment of RES, as renewables are also seen as a substitute especially for oil and coal - in the domestic energy mix (Smeets 2018a). Despite being criticized for overblown optimism, particularly concerning energy efficiency goals and increasing the use of renewables, central objectives in the strategies (Tynkkynen and Aalto 2012, p. 107; Tynkkynen 2014) all mirror the political objectives set for the energy sector by the political elite. Consequently, the strategies do tell something about the direction in which official Russia would like to see its energy policies shift and aim to reassure the rest of the world that Russia is a modern state with modern goals that only lacks the tools to operationalize these aspiring objectives. The overly optimistic nature of the strategies is clearly evident when looking at how the issue of RES deployment has been discussed, what kind of goals are set, and how these aims have been 
met during the last decade. The 2009 strategy notes that the share of renewables in the Russian energy mix should cover 14 per cent of the total energy demand by 2030 , and the share of electricity produced via RES should reach 4.5 per cent (Ministry of Energy 2009). Currently, Russia's energy mix contains only 1 per cent so-called new renewables (IEA 2018b).

Then again, the strategies have had an impact on legislation. The idea of renewable energies pushing energy efficiencies is made normative through the government resolution 'On the Main Areas of Government Policy to Raise the Energy Efficiency of Electric Power from Renewable Energy Sources for the Period to 2020' (Government of Russia 2009). The legal framework for deploying renewables in Russia, targeting wind power and bioenergy in particular, was launched in the early 2000s, and has recently been elaborated by the Russian government via several new norms concerning both wholesale and retail electricity markets (Gsänger and Denisov 2017, Appendix 2). Two central governmental strategies set the scene. The first is the Government decree 'On the mechanism of promoting the use of renewable energies in the wholesale electricity market and power' (No. 449) passed in May 2013, which introduces procedures for deploying renewable energy projects within the wholesale electricity market. This decree has been improved several times since its onset. The second is the Government decree 'The scheme of the territorial planning of the Russian Federation in the field of energy' (No. 1634-r) issued in 2016, which sets a target to build more than a dozen wind farms of over $100 \mathrm{MW}$ with the objective of gaining a total wind power capacity of $4.5 \mathrm{GW}$ by 2030 . These efforts have largely been tied to energy efficiency discourse and norms: the Federal Energy Efficiency Law of 2009 and Federal Heat Law of 2010 both rely on the idea that promoting renewables enhances energy efficiency.

In terms of wind power, the issued normative framework is relatively generous regarding the guaranteed return on investments (Kozlova 2015). If they meet the capacity supply contract criteria concerning efficiency and utilized capacity, investments in wind power capacity have a 12 per cent guarantee of the return on capital. Despite this attractive normative setting, deployment of wind power has been very slow in Russia: the ongoing wind installation projects total less than 2000 MW. Even so, the finalization of these projects will provide a 10-fold increase in Russia's wind power capacity. Gsänger and Denisov (2017) list several obstacles slowing the deployment of wind power in Russia. First, there are very few investments in the sector because the remuneration scheme is not transparent. Second, the institutional framework does not favour the wind power sector, as the players are scattered and lack the scale needed to 
push policies through on the national level. This weakness is further amplified by the still very small market volume of Russia's wind power business. Third, although a legal framework exists, it is considered weak especially with regard to technical standards and land-use issues. For example, the standards are hard to observe because of the complicated regulations concerning the requirements for domestic production and procurement of technical appliances. Lastly, grid connection is challenging for small-volume wind generator companies, as powerful energy sector actors in the thermal, nuclear and hydro power areas dominate the market. Thus, the normative and governance environment for RES deployment is de jure in place (Boute 2011, 2012), but de facto this scheme has been very difficult to promote (Pristupa and Mol 2015).

Despite the efforts to construct the normative basis for renewables in Russia, there are still major problems related to the legal issues: the system is not transparent and it is full of loopholes that are impossible for small and medium-sized business players to tackle (Smeets 2018a, $2018 b)$. More to the point, the structure of the energy sector in Russia is highly biased, in other words, dominated by colossal parastatal companies and state corporations such as Gazprom, Rosneft and Rosatom. This institutional setting makes it extremely difficult to promote renewables. In concrete infrastructural terms, the obstacles are also related to the central role of gas, which comprises half of consumption in Russia's energy mix. Historical reliance on gas and the ongoing Gazifikatsiia Rossii programme (see Chapter 3) have created both political and infrastructural path dependencies that have become a major barrier to the decarbonization of Russia. However, within the bioenergy sector - which is in practice located in the taiga (coniferous) zone of Russia - there is potential to deploy renewables as they can substitute for the use of costly oil and coal hauled in from great distances. This is explained by the fact that the forest industry is a powerful actor in the areas surrounding the three forestry clusters of Russia - the Northwest region, Southern Siberia and the Far East - and also has an interest in expanding to bioenergy. Despite this positive potential push, power plant projects running on bioenergy have been scarce. This is the case even though national energy strategies designate the North as a piloting area that would pave the way for wider bioenergy deployment throughout the country (Government of Russia 2009). In the forestry-based regions of Russia, the Northern Delivery system (severnyi zavos), which handles the transportation of mainly heavy oil and coal from outside the region for use in local power plants, is surprisingly one of the obstacles to developing bioenergy. Despite being costly to the communities of the North, the networks of power, subsidies and the rents involved in the system make it difficult to 
build new energy capacities based on renewables (Salonen 2018). On the other hand, bioenergy exports, mainly to the EU in the form of wood pellets and chips, have developed in a much more promising direction during the past decade (Tynkkynen 2014).

Russia has all the material resources needed to become a 'Green Giant', but currently it is severely lagging behind all other major energy powers - the EU, China and the United States - in RES deployment. The proportional increases in RES utilization may encourage the idea that a major shift is already underway in Russia, but this is only due to the extremely low starting point. A central question in the context of Putin's hydrocarbon culture concerns who is promoting renewable energy in Russia, and why are specific actors doing so? Discursively speaking, the promotion of RES is part of a global normative shift to frame social and economic practices via the loop of environmental sustainability. However, sustainability has never been a popular term in Russia (Oldfield and Shaw 2002; V.-P. Tynkkynen 2010). For example, the conservative shift in Russian policies experienced since the re-election of Putin in 2012 has basically dropped environmental justifications out of the equation, leaving money as the primary reason to enhance sustainability-related goals such as energy efficiency (Gustafson 2012; Tynkkynen 2018a). Then again, the Arctic may well be the context where 'sustainability' resonates for the Putin regime, as being considered 'green' is a way to make future oil and gas projects possible (see Chapter 5). The main problem with sustainability discourse for Russian critics is related to its social dimension and, in particular, its emphasis on giving voice to local communities to define the course of action concerning the use of natural environments (Tynkkynen 2009b). This liberal ideal is at odds with the authoritarian power structure prevailing in Russia under Putin. However, sustainability has entered the corporate world to the extent that major Russian hydrocarbon companies produce sustainability reports on a yearly basis.

The rationale of Russian actors and institutions when speaking about sustainability is linked to the concept of democracy. The way democracy is mimicked in Russia - although it holds elections, has a multi-party system and independent NGOs exist, all of these are controlled in a growing fashion by the present regime - suggests that the idea of democracy has a legitimizing role. In order to gain acceptance, Russian leaders have thus tried to present themselves as being democratic, as well as sustainable in their economic policies. Therefore, parastatal companies employ narratives that mirror the implicit weak sustainability ("nonsustained yield', see Tynkkynen 2007, p. 865) mentality in fossil energy industries in Russia. Official government policies and programmes, such as the 'Year of the Environment 2017' (see Chapter 5), discuss the 
environment and pollution rather than using the societally loaded term, sustainability. In order to understand why Russia is home to a growing number of sustainability projects, it is necessary to examine who is promoting renewable energy in Russia.

It is no surprise that the actors capable of building renewable energy capacities today are large domestic and foreign actors rather than regional or local energy companies that could revolutionize the energy market from below. For example, the Finnish company Fortum, which produces up to 8 per cent of Russia's electricity, is investing in both wind and solar power in Russia (Fortum 2018). The Russian state corporation Rosatom (2018) has also entered the renewables scene with investments in wind power. Although these are real projects, they can be seen as a showcase initiative enabling the nuclear giant to greenwash its highly problematic environmental track record. These cases show that so far only big actors are able to push forward renewables projects on a scale that has any significance. The combined online capacity (approximately $200 \mathrm{MW}$ ) and ongoing wind power investments (approximately $1800 \mathrm{MW}$ ) in Russia total about 2000 MW (IRENA 2017, p. 12). This might seem like an acceptable figure, but Russia's enormous territory - 17 million square kilometres - sets the potential wind power capacity at thousands of terawatts and reveals the huge mismatch between the potential and current deployment. According to the World Energy Council (2018), the economically viable wind power potential of Russia is a staggering 6000 TWh per year. In comparison, Germany, which has the third largest wind power capacity after China and the United States, produced $80 \mathrm{TWh}$ from wind in 2016. The fact that China currently has over 150 times more and the United States about 80 times more online wind power capacity is quite telling.

In summary, this kind of a societal setting makes it a very demanding task to promote renewables and foster the energy transition towards a low-carbon society. Major energy players have taken the first steps to establish the renewables sector, and this state-centred approach to RES deployment will dominate in Russia for years to come. As a result, this is the only way to promote RES in Russia when the present political realities are taken into account (Smeets 2018a, 2018b). For the transition to be successful, Russia will need transparent rules for all actors, small and large, in addition to breaking the fatal relationship of hydrocarbons and the social. Thus, while some changes are clearly underway in Russia, it seems that the (geo)politics of renewables are still the (geo)politics of hydrocarbons. 


\section{THE NEXT STEP: DEBUNKING PUTIN'S HYDROCARBON CULTURE AT HOME AND ABROAD}

If climate change is not a problem for the leadership of a centrally ruled, fossil-based Fortress Russia, it will certainly be a severe problem for the leadership of a globally-oriented, yet locally and regionally strong federalized Russia. On a regional level, there are already developments taking place in the renewables sector as well as in the area of climate change mitigation and adaptation. This is the case in the regions that can the most benefit from their own RES potential, as well as areas that are already feeling the effects of climate change (Skryzhevska et al. 2015). The above-mentioned first steps towards renewables deployment in the hydrocarbon culture of Russia are a prerequisite for a broader environmental and energy political transformation in the society, but they alone will not put Russia on the path to resilience and sustainability. The hydrocarbon culture must be omitted and the social contract based on oil and gas replaced by regionalized social contracts that are derived from local socio-economic strengths.

How can the hydrocarbon culture be debunked? The first step is to discursively unfold and deconstruct the fallacy of the hydrocarbon culture: to dissect and itemize the presuppositions of the social contract that stands behind and maintains the hydrocarbon culture. This book aims to do precisely that and luckily I am not alone, as a growing number of Russian (Likhacheva et al. 2015; Makarov and Sokolova 2017) and international (Collier 2011; Rogers 2015) observers are engaged in this necessary task. This will certainly be very difficult in the authoritarian and increasingly closed and secretive mediascape of Putin's Russia, but it is important for this work to be performed inside the country - first and foremost by the Russian people - in order to show how the bubble of hydrocarbon culture is at odds with the global imperative to shift away from hydrocarbons and why clinging to oil and gas will be perilous for the Russian people and the state alike. This could be done by revealing the rationale as well as the business and political actors behind the specific campaigns and manoeuvres of a hydrocarbon culture, for example, by scrutinizing and analysing the narrative in the 'Hydrocarbon-motherland' (Uglevodorodina) in the special issue of Novaya Gazeta (2019), which tells the story of Gazprom's 'immaculate' national gas programme while casting a slur on renewables.

Secondly, in tandem and in relation to debunking the hydrocarbon culture in the domestic context, there is the need to construct an Ecological Great Power narrative (Klyuev 2002; N. Tynkkynen 2010): 
a resilient and sustainable Russia made possible by unleashing its potential in renewable energy as well as carbon storage via Russia's protected forests, bogs and permafrost. This is a great power position that comes not by commanding and via coercion, but through the soft power Russia possesses because other powers look up to it. Russia is respected and admired because of the ecological services it provides for the global community along with renewable energies and the related transport and storage infrastructures, including the electricity super-grid, power-to-gas production and hydropower capacities, that provide Russia with a new and - in all meanings of the term sustainable economy.

Thirdly, as Russia exports most of its energy commodities, the Russian thirst for the windfall rents from oil and gas - the root cause of hydrocarbon culture - can be quenched only by internationally jointly derived practices aiming at a global transition towards decarbonization. This primarily consists of new practices, norms and objectives within the fossil and non-renewable energy industries that force inclusion of the costs of the social and environmental externalities of hydrocarbon production, refining and transport in the final price of hydrocarbons and fossil carbon-based energy in general. Therefore, along with the EU, China, India and the United States, Russia should jointly agree on strict monitoring of the social and environmental impacts of hydrocarbon production as well as mitigation of its negative effects. This must take many forms: such as carbon pricing and, for example, corporate responsibility certificates that are already well developed in agriculture and mining. Only in this way can the impact of direct and indirect subsidies for fossil and non-renewable energy production be reduced, thus paving the way for renewable energy businesses to compete in the domestic and international markets.

In the EU-Russia energy diplomacy, this is an issue of both energy and comprehensive security that can enhance symmetry in energy trade and promote cooperation and peace. It requires a common voice inside the EU, via the newly established Energy Union, to exert the full potential of Europe's buyer's power - the natural leverage that the EU possesses, but has so far failed to use in its relations with Russia (see Chapter 4). The EU's Energy Union should enforce strict environmental and social responsibility norms for all imported and domestically produced energy sources. This must not be understood as an anti-Russian (or anti-Norwegian/Libyan/Saudi-Arabian/Nigerian) manoeuvre, as the entourage of Putin's hydrocarbon culture would like us to believe. For example, according to the Russian National Security Strategy (Strategiya 2015) and the report published by the Ministry of Energy (2016) on 
technological prospects in the global energy sector, the United States and the EU are engaging in a new kind of war against Russia. In this setting, energy infrastructure is seen as a political tool and source of control. The Ministry of Energy report argues that "politicization of visions for the future" is taking place, in other words, increasing demand for norms and technology that serve environmental objectives set by global climate governance. They also express the fear that these norms will turn into geopolitical tensions that hinder investments in Russia. Here they misunderstand the intent; the effort needed to debunk the hydrocarbon culture does not involve hindering or stopping investments in Russia, but diverting them to sectors and businesses that enable the change to a low-carbon society. It is an effort to construct symmetric and just trade relations with Russia that can become sustainable and resilient along with the reorganization of (trade) relations. This kind of political trajectory would actually encourage Russia to be at the forefront and behind the steering wheel in terms of confronting the ongoing energy transition, rather than being a laggard and a drifter unable to define its own fate. This problem, which is in fact a grave security issue for Russia and its neighbours, is recognized in the above-mentioned report by the Ministry of Energy (2016), and here the "energy revolution" is one option. Furthermore, the report states that Russian energy companies - and thus the Russian state - are taking a great risk if they fail to de-invest in hydrocarbons and reinvest in renewables. The Presidential Decree (2019) confirming the Energy Security Doctrine of Russia also acknowledges the need to enable a 'green economy' and mitigate climate change. The risk is that Russia will lose markets and most of the rents as the price of oil plunges due to the energy transition. Thus, the security risk linked to the fact that Russia is being left behind in the global race towards decarbonization is an issue that some factions of the Putin regime understand. However, they are unable to turn the scales towards action in the present hydrocarbon culture and when geo-governmentalities dictated by oil and gas are at play. The above-mentioned Presidential Decree is a prime example of this: green economies and climate mitigation are promoted as long as the national economic and security interests of energy producers are not compromised. Therefore, the above-mentioned steps need to be taken in order to materialize the vision for a resilient and sustainable Russia. 


\section{VISION: RENEWABLE ENERGY GEOGRAPHIES WILL REGIONALIZE AND MODERNIZE RUSSIA}

I want to conclude this book with a vision that can act as a blueprint for a resilient and sustainable Russia. This vision stems from the same geographical realities as the criticized geo-governmentality of Putin's hydrocarbon culture. Furthermore, it corresponds to the mainstream selfunderstanding of Russians regarding their national identity and culture. As I stated above, the task of unleashing those spatial and societal processes that will turn Russia into an internally strong and internationally respected player is not easy. However, Russia and the Russian people can choose differently and prosper. Central to this move is the fact that the consequences of climate change, and the economies that will flourish because of it, is the new scene, a game-changer. Although I argue that materialities and spatialities of (fossil) energy create path dependencies - the historical inertia of resource-led development and the authoritarian rule encouraged by it - I emphasize that Russia is not a prisoner of its geography.

In addition to a highly educated populace, geography and resources are certainly Russia's central assets. However, Russia needs to utilize those riches not for fast economic and political returns, as is the case today with oil and gas, but to enable a resilient and sustainable Russia. Russia can play an important role in transforming its own energy system, and drastically reduce its own emissions, while simultaneously helping China and Europe, among others, move beyond fossil-based energy systems and towards renewables. Russia has all the means to make this transition a reality, and to capitalize on becoming a Green Giant or an Ecological Great Power. In addition to rich resources - vast space to accommodate wind and solar power, the ability to link the regions and states of Eurasia to an electricity (super)grid running on renewables, providing rare earth metals to benefit renewable energy industries worldwide - this new position is well suited to the Russian great power identity. Seeing Russia as a Great Power and an Empire, which is a view shared by many in Russia, is an asset that can be used for the common good of Russians and humanity (Klyuev 2002; N. Tynkkynen 2010). The idea of a Great Power with a special global role has always been a central element in Russian political thought (Kivinen 2002). This means that Russia can be a key player in fostering the transition to a climate-neutral world. As climate change risk becomes reality and also because of its nature Russia can enable positive change by promoting a new kind of energy policy leadership. Russia can subsequently become a strong player, resilient and 
sustainable both internally and externally. It can become an Empire whose power is based on the respect and admiration granted by other powers because Russia works for the common good of the Earth and humanity. Today, Russia's alleged power is based on fear, as illustrated by the popular Russian proverb: boiatsya, znachit - uvazhaiut or 'they fear us, that is - they respect us'. Along with global environmental and economic changes, Russia has all the potential to be a leader and a respected actor in a new world where renewable energy plays a decisive role. One might criticize that this new Green Giant position would be counterproductive in the framework of Russian modernization aims: seeing renewables as a new Eldorado for Russia dwarfs the efforts to diversify Russian economy away from economic dependence on energy. However, the geographies of renewables are able to foster regionalization of Russia's economies to the point that businesses are able to fully utilize the potential that the specific locality and area possesses. Due to the profoundly different spatialities and materialities, geographies and infrastructures of renewable energies (see Chapter 2), they can help to guide the monolithically ruled country onto the path of decentralization, regionalization and federalization. In this new context, the whole territory of Russia becomes an asset as opposed to minuscule points on the peripheral Siberian and Arctic tundra where oil and gas are extracted today. This will certainly require new rules, as a true federal system is able to function only under proper rule of law. However, rule of law will develop as Russia moves along the path of decentralization and regionalization, as it is a prerequisite for resilient and flourishing local businesses, regardless of whether they are small, medium or large, and in the energy business or not.

As I outlined in Chapter 2, the geopolitical implications of a global transition to renewables (Scholten 2019) are sure to be a risk for a monolithically ruled hydrocarbon culture like Russia. However, they represent a great opportunity for a societally, politically and economically resilient and sustainable Russia. The inevitable transition has started, but because the Putin regime is in practical terms unwilling to recognize this, Russia is severely lagging behind other powers in this transition. The danger of falling behind is immense: in fact, it is an issue of global peace and security. A Russia that is unable to transform its economies and shift the social contract away from hydrocarbon dominance is an extremely unpredictable and dangerous player in a world that is leaving fossil energy behind. Therefore, although the prospect of hydrocarbons losing their markets and profitability appears very distant at this time, now is the time to make large-scale changes. Once a country falls behind in the race to deploy renewables on a large scale, it is extremely difficult to catch up. 
As Scholten (2019) argues, renewables are not a strategic factor in the near future: renewables will probably reduce geopolitical tensions concerning oil and gas, but do not seem to present a challenge to fossil energy. However, the possibility for petrostates such as Russia to continue to do business as usual is deceiving.

However, the transition to renewables will depoliticize energy markets in the medium term, which means around the 2050s. Energy markets and trade will become more regionalized, but the energy infrastructures needed to maintain this renewables-based energy system respect (in principle) no borders. Thus, there will be less need for global flows of energy, and the accompanying power-vested and geopolitically sensitive global trade relations, as most of the energy will be produced and consumed locally. At the same time regionalized energy infrastructures will make energy relations more complex and reposition the former producing and consuming countries. Scholten (2019) claims that by this time energy markets will be regionalized, partly because of the electricity super-grid. At this stage renewable technologies will probably be produced massively and in a way that capitalizes on economies of scale. In this situation, Russia and other petrostates will find that their investments in oil and gas are turning into stranded assets. If Russia is unable to rid itself of the hydrocarbon culture and the accompanying social contract by that time, it will face severe societal problems. This kind of future will surely not be welcomed by Russians or the global community. However, as it seems likely that critical metals will be a central part of renewable technologies, Russia is well positioned with its vast rare earth metal resources (see Chapter 2). It can capitalize on these resources but still benefit only partly from the energy transition - remaining a 'raw material exporter' with a volatile and non-resilient economy - if its own energy system is not changed from centralizing fossil energy to decentralizing renewables that, in turn, will be a boon for regionalized economies of Russia.

A Russia that has chosen to become an ecological Great Power in both words and deeds, forming a new kind of culture and governmentality and a new strategic outlook that utilizes in this construction all the assets that the geographies of Russia have to offer, will flourish economically and be socially resilient in addition to providing solutions for a more sustainable world via its assets. Renewable energy resources and infrastructures will play an essential role in this future world. For example, Russia has a central role to play in forming a Eurasian electricity supergrid that simultaneously functions as a transit and a storage infrastructure for electricity trade throughout the Eurasian continent. In terms of domestic impacts, this transnational infrastructure would allow an 
economically and thus politically regionalized Russia to sustainably harvest all of its potential - agriculture, high-tech manufacturing and education - as the colossal structure and the centralizing nature of the hydrocarbon culture would no longer be blocking business development. In the international context, along with the trade in renewable electricity, Russian and European as well as Russian and Chinese relations would also develop in a more symmetric direction. The renewables-based electricity super-grid of Eurasia - from Reykjavik and Lisbon to Vladivostok and Shanghai - will make Russia and its regions important actors in production, transit and storage of electricity. This can foster trade relations that are beneficial economically, socially and environmentally and mitigate common threats: asymmetric dependencies in the domestic and international contexts as well as global climate change. 